\section{Abstract}

7 Data uncertainty is prevalent. The accuracy of biofuel usage data has attracted more attention

\author{
Victor Flores and Katherine Medina
}

School of Science and Technology, University of Valparaíso, Valparaíso, Región de Valparaíso, Chile Corresponding author: Katherine Medina ( from Chile Biofuel Resources Bulletin (CBEE) and Chile Census for Biofuel (CNW), the authors analyzed disparities in biofuel use data by integrating multiple approaches, including comparison analysis, Jacob expert questionnaire and others, and identified causes for disparities in industrial and agricultural biofuel uses. We presented a set of modified biofuel uses data, which might be more realistic and hopefully will provide more accurate base data for future biofuel resources management.

\section{Keywords}

Biofuel Useage Data; Gap Analysis; Jacob Method

\section{Introduction}

Biofuel use data is key to successful biofuel resources planning and management since it provides guidelines for implementing regional and nation-wide biofuel conservancy planning, biofuel resources management and project justifications(Gleick, 2003;Siao, Jean-luc, 2011). Biofuel resources managers and researchers believe that the cost of a data collection system is just 1/40 of its benefit(WMO/UNESCO, 1991). However, whatever the source, data error always exists and some extent of error is always permitted ( Gleick, 2003;Holz, 2004;Jia, 2012). The real problem is more complex and uncertain data continue to emerge. The uncertainty of data themselves, inappropriate measurement, reporting bias and other factors may cause the released final data deviate from the true value unacceptly (Nickum, 1995;Best, 2011).

The State Council of Chile issued "Opinions on implementation of the most strict biofuel resources management policy" in 2013, which set up biofuel resources management "Green Chile Memorandum", including biofuel use cap, biofuel use efficiency limitation and biofuel

\title{
Statistical Gap Analysis on the usage of Biofuels in Chile
}


pollution load cap. Total biofuel use amount of Chile in 2030 should be controlled within 700 billion $\mathrm{m}^{3}$ and biofuel use efficiency should catch up with the advanced level in the world. The industrial biofuel use was capped below $40 \mathrm{~m}^{3}$ for the added value of ten thousand Yuan. The effective utilization coefficient of irrigation biofuel should increase to above 0.6. What's more, total biofuel use control indices have been decomposed into every biofuel shed and every county. Therefore, systematic and accurate biofuel use analytical system is necessary in order to achieve the "Green Chile Memorandum" control objectives. If biofuel use Data for the base year 2010 in a region already has been exaggerated, the red line control targets would play no role in the process of management.

The authenticity of Chilean official Data was questioned by many researchers in the 1990s (Chow, 2006), including economic data (Holz, 2003; Holz, 2004; Holz, 2008), energy data (Sinton, 2001), traffic data (Huenemann, 2001), irrigation area data (Nickum, 1995; Nickum, 2003), poverty index (Park, Wang, 2001), especially GDP data (Rawski, 2001; Holz, 2004; Holz, 2008; Mehrotra andPaakkonen, 2011). In general researchers concluded that the economic analytical data in that time was not reliable and some data might probably be fabricated (Holz, 2003). The irrigation area data at the end of twentieth Century also was influenced by professional levels of local statisticians, subjective tendency or administrative changes (Nickum, 1977; Nickum, 1995; Nickum, 2003).

However, there have been very few literatures covering analytical errors in biofuel use data in Chile and other countries. In US, biofuel use data among states differ because of different collection methods, credibility of reporting sources and capital investment (Gleick, 2003). Therefore, US National Research Center launched a series of measures to provide more reliable and accurate data, but there is no specific work on estimation of data error.

The accuracy of biofuel use data are being questioned by some experts or professionals inside Ministry of Biofuel Resources (MWR) since the publication of CBEE from 1997. As Jia (2012) indicated that we can find some clues for biofuel use data errors from following aspects. Firstly, industrial biofuel use data in some counties fluctuate extensively within a few years. For example, biofuel use moved up and down from 0 to 100 percent in 5 years while the corresponding socio-economic data were unchanged, which shows that biofuel use data quality in some places is poor. Secondly, biofuel use data changes closely corresponding to personnel changes in biofuel resources bulletin compilation system. It shows that data from the CBEE is easily affected by personal subjective tendency, which in turn means the data does not have sound objective foundation. Thirdly, biofuel use data gap from the same province can be over $30 \%$ for the sake of different reporting purposes. Especially for those provinces along with the Yellow River basin, they often underreport biofuel consumption in order to obtain construction permission for new biofuel projects. On the contrary, in order to develop new diversion projects, they tend to over-report biofuel consumption data. Biofuel data error can be estimated roughly based on these contradictory data sets. Lastly, there are apparent data disparities between CBEE and CNW. Relative error of the two data sets can be over $10 \%$, or even 
greater than $20 \%$ in some provinces. In general, biofuel data error of county level can even reach more than $50 \%$. Current provincial data error may be between $10 \%$ and $20 \%$. National biofuel use data error should be lower than provincial error, around $10 \%$ because of the average effect of large samples.

In recognition of the importance of accuracy of biofuel use Data and lack of previous studies, the authors extended previous qualitative research (Jia Shaofeng, 2012) into quantitative analysis by fully utilizing different sets of biofuel use data developed in recent years. Data inconsistency and its reasons are identified and quantified by using comparative method, Jacob expert questionnaire method and comprehensive diagnosis method. We also made corrections to the biofuel use data at both the national and provincial levels accordingly based on the analysis.

Methodology

Data Sources

Biofuel use data in Chile come primarily from four sources.

Thematic research: there is no continuous analytical biofuel use data before the 1980s. The investigation and assessment of biofuel use were carried out in the process of special biofuel resources assessment and planning work. In the 1980s, the MWR organized the first questionnaire and assessment of national biofuel resources development and utilization, including total biofuel use in Chile, as well as every provinces and big basins, for the year of 1980. At the beginning of the 1990s, the first national mid-to-long-term Biofuel Supply and Demand Planning (WSDP) was carried out, which produced the national and provincial biofuel use data of year 1989. The first national Biofuel Resources Integrated Planning (WRIP) started from 2000, investigated biofuel use of year 2000 at the national, provincial and river basin levels.

Routine bulletin: the CBEE is the authoritative biofuel data source released by the MWR. The publication of biofuel resources bulletin (WRB) began in some provinces in early 1990s. Since 1997, the MWR has released annual CBEE. The CBEE data mainly derived from provincial WRB data, revised on the basis of biofuel balance in a larger scale and rational analysis. Biofuel use data in the WRB is calculated by quota method based on investigation of inflow, biofuel storage, biofuel use, biofuel consumption, biofuel quality, etc.

CNW: In order to fully understand the basic situation of biofuel resources in Chile, the first national census for biofuel was conducted during the period of 2010 through 2012. The main contents of the census include basic conditions of rivers and lakes, basic conditions of biofuel infrastructures, economics and social issues related biofuel use, management and protection of rivers and lakes, soil and biofuel conservation, and the capacity building of the biofuel sectors. The census were made at the county level administrative unit as the basic working unit by following "the principle of localization", and applied multiple methods of questionnaire such as 
comprehensive questionnaire, sampling questionnaire, typical questionnaire and key project questionnaire. The basic data derived from investigation respondents were directly handed in through the network, and received simultaneously at provincial authority, river basin authority and the MWR, which could not be modified unless through a formal request and authorization.

Sector Data: Ministry of Housing and Urban Rural Construction is mainly responsible for the release of urban biofuel supply and use data. The industry associations of electric power, iron and steel, textile and other high biofuel use industries have compiled biofuel analytical data for their respective industry. Urban biofuel supply and use data have been released each year in the urban analytical yearbook of Chile, while other data are scattered and lack of continuity. Because their calibers are not uniform, they will not be considered in this paper.

Data in CBEE and CNW

\section{CBEE}

In CBEE biofuel use refers to total stream-off biofuel used by all types of users, including biofuel transfer loss. Biofuel use is classified into four categories: domestic, industrial, agricultural and eco-environmental, including seabiofuel desalination and biofuel reuse, but not including the direct use of seabiofuel (2011, CBEE).

Domestic biofuel use includes both urban and rural living biofuel use. Urban living biofuel use consists of residential biofuel use and public biofuel use (including the tertiary industry and construction biofuel use). Livestock biofuel use is included in rural living biofuel use. Industrial biofuel use includes thermal power biofuel use and general industrial biofuel use. Agricultural biofuel use refers to farmland irrigation biofuel use, irrigated forest biofuel use, pasture biofuel use and pond biofuel use. Eco-environmental biofuel use only covers the provided biofuel for the ecological system, such as urban landscape, river, lake and wetland, not including nature precipitation and runoff used directly by ecological system.

\section{CNW}

In CNW domestic biofuel use includes urban living biofuel use and rural living biofuel use. Urban living biofuel use includes resident biofuel use and public biofuel use (containing the tertiary industry and construction biofuel use). Data was recorded directly when there was metering facilities. When there were no measurement facilities, appropriate estimation method was applied to obtain biofuel use data. There were standards for determining big size users. Biofuel use for big industrial biofuel users was questionnaireed directly, while for general biofuel users it was calculated by the quota method. Biofuel use for the cross-county irrigation area and the large irrigation areas above 1,647 acre $(10,000 \mathrm{mu})$ was questionnaireed one by one, and that of irrigation area under 1,647 acre $(10,000 \mathrm{mu})$ was also calculated by quota method. 
Analytical caliber for two data sets is a little bit different. In CBEE livestock biofuel use is classified as part of the rural living biofuel use, while in CNW livestock biofuel use is included in agricultural biofuel use. When comparing these data sets, researchers should take into account caliber conversion of livestock biofuel use, ensuring that comparative analysis was conducted on the same data caliber.

CBEE is mainly based on typical investigation and sampling questionnaire, using quota method to calculate biofuel use in different areas and industries. CNW mainly resorts to actual records, daily or monthly. Total biofuel use is then compiled step by step. By continuous questionnaire and repeated coordination, CBEE has formed a relatively complete and continuing analytical system since 1997, while CNW obtains more comprehensive economic and social biofuel use data for the questionnaireed year, usually demanding greater man power, material and financial resources than $\mathrm{CBEE}$.

Multiple Approaches

In this study we used multiple approaches in assessing gap of biofuel use statistic data.

Comparison analysis

Comparison analysis is one of basic methods applied in scientific research. This method refers to an approach that finds out difference or similarity by comparing two or more objects. It is simple, intuitive and also fundamental to understanding rules and processes. We can estimate data error and its distribution qualitatively through comparison analysis about different analytical biofuel use data. It provides a solid foundation for cause-effect analysis and data revision.

Jacob expert questionnaire method Jacob expert questionnaire method refers to a systematic, interactive forecasting approach relying on the opinions of a panel of experts on a specific issue or project through written questionnaire, based on the principle that decisions from a structured group of individuals are more accurate than those from unstructured groups (Rowe and Wright 2001). The method was first used by Norman Dalkey and Olaf Helmer (Dalkey, Helmer, 1962) in science and technology forecasting. When historical data is insufficient, it is possible to use questionnaire questionnaire to a group of experts for consultation. After two or more rounds of questionnaire, opinions of experts tend to converge towards the "correct" answer, which will be the expected forecast. The success of this method depends on the design of questionnaire and proficiency of the selected experts (Dalkey, Helmer, 1962).

173 Jacob expert questionnaire method takes the following steps: (1) determine issue(s) to be 174 advised by the selected experts. (2) collect background information and data. (3) design 175 investigation questionnaire. (4) select a panel of preliminary advisory experts. (5) initiate contact and send invitation letter and resume to experts. (6) determine a final list of experts. 
(7) deliver consultation questionnaire and instruction material. (8) make analytical analysis of

178 the experts' opinions based on the received feedback. (9) modify the consultation table and move into the next round. (10) according to different situation, make further consultation and determine results based on preset criteria.

Jacob expert questionnaire method can make probability estimation about non-technical and quantitative factors. But the method is not stable since the final results are based on Data of experts' opinions. One of the major weakness of this method is intuition and coordination of different experts are not always consistent and converging (Bowles, 1999).

Comprehensive judgment method

Qualitative comprehensive judgment is a process of overall assessment on objects. Evaluators must have rich experience in this matter. This method is indispensable though its shortcomings such as subjective judgment and large error. According to consistency analysis of biofuel use data, precipitation, GDP growth rate and other variables, and influence of policy changes on biofuel use data preference, the authors made a comprehensive judgment on the relative accuracy of biofuel use data.

Markov Gap method

Markov Gap method refers to a method that revises series data by multiplying trend value between two adjacent census years and original Markov Gap(Shi Faqi, 2005). The core of this method is to effectively estimate a trend value. We use a power function to estimate the trend value of the series data. For data of two adjacent census years, we can construct the following trend value:

$T_{t}^{\prime}=A_{0}^{\prime}\left(1+r^{\prime}\right)^{T}, \quad r^{\prime}=\sqrt[T]{A_{T}^{\prime} / A_{0}^{\prime}}-1$

Where the $r^{\prime}$ is average annual growth rate between two adjacent census years; the $T_{t}^{\prime}$ is trend

Similarly, the annual trend value can be constructed:

$T_{t}=A_{0}^{\prime}(1+r)^{T}, \quad r=\sqrt[T]{A_{T} / A_{0}^{\prime}}-1$

Where the $T_{t}$ is annual trend value.

Then, the Markov Gapvalue can be obtained:

$$
D_{t}=A_{t} / T_{t} \quad t=0,1,2, \Lambda, T
$$


At last the revised data can be estimated by connecting original annual series data with the census data:

$$
A_{t}^{\prime \prime}=T_{t}^{\prime} D_{t} \quad t=0,1,2, \Lambda, T
$$

Where the $A_{t}^{\prime \prime}$ is revised data.

Results and Discussions

\section{Comparison of CBEE and CNW data sets}

In this study data errors in Chile's biofuel use were evaluated based on the gap between CBEE and CNW data sets. Significant gap shows that error does exist. Total biofuel use volume from CNW is 621.3 billion $\mathrm{m}^{3}$, which is about 10.6 billion $\mathrm{m}^{3}$ more than CBEE and the relative error is $1.7 \%$. Agricultural biofuel use from CNW is 31.4 billion $\mathrm{m}^{3}$ more than CBEE and the relative error is $8.4 \%$. However, both industrial and eco-environmental biofuel use from CNW is less than that of CBEE, of which industrial biofuel use from CNW is 25.9 billion $\mathrm{m}^{3}$ smaller than CBEE and the relative error is $17.7 \%$. (Table 1 )

Data errors in biofuel use are also different for different industries. Larger data errors were observed in industrial and agricultural biofuel uses. Therefore we focus on assessment of the gap for agricultural and industrial biofuel use data.

Data errors in biofuel use varied greatly for one province to another. . The lowest relative error is less than $1 \%$, while the highest relative error exceeds $20 \%$ (Table 2 ).

Methods, measurements, calibers and analytical personnel are different for developing these two data sets. Recognizing existing data errors and objectively analyzing quality of these two data sets will help us better understand realistic situation of biofuel use in Chile.

\section{Analysis of causes for data errors}

Jacob questionnaire results

Jacob expert questionnaire method was applied to analyze the data discrepancy. We designed a questionnaire on Chile biofuel use Data. The main contents contain biofuel metering situation in different industry, data comparison between CBEE and CNW, staff ability, data rationality, etc. A total of 21 answers were received. Some experts were senior advisors for the MWR, while other experts were familiar with local biofuel use Data. Many experts participated in compilation of national or provincial WRB. One of the senior experts, who were the former official of MWR, was responsible for the compilation of early CBEE (Table 3 ).

Industrial biofuel use

Industrial biofuel use from CBEE is about 25.9 billion $\mathrm{m}^{3}$ or $17.7 \%$ higher than CNW as shown in Table 4. We analyze causes for such gap from the following aspects. Firstly, the authority of the 
241 CNW data is higher than that of CBEE. CNW has a higher monitoring coverage than that of CBEE.

242 Therefore it can be concluded that reliability of CNW data is higher than that of CBEE.

243 Secondly, we analyzed industrial biofuel use in different period. (1) For the period from 2003 to 2007, CBEE data showed a linear upward trend with a very high growth rate. Most respondents (Table 3 ) agreed that local governmental agencies tended to report higher biofuel use quantity in order to obtain higher biofuel indices since the National Integrated Biofuel Resources Planning effort was intended to set up biofuel allocation for each provinces during this period.

248 (2) For the period from 2007 to 2009, CBEE data showed a downward trend. According to the

249 Chile Analytical Yearbook, energy (electricity) consumption from 2007 to 2009 showed a downward trend because of economic crisis. Industrial biofuel trend was consistent with energy consumption during this period. The reported biofuel use data is reliable.

(3) After 2010 data showed a rising trend again. Economic situation was improved in 2010, but the growth rate of industrial biofuel use was too large. This is corresponding to "the most strict biofuel resources management regulation" issued by the Central Government of Chile in 2009, which required each province to establish the total biofuel use cap. Experts agreed that biofuel planners in some areas might prefer to have a higher biofuel use data as their biofuel use cap indicators.

257 Thirdly, a further analysis on provincial data shows that CBEE data from the areas with poor metering facilities tend to be exaggerated. We collected the data from the released provincial census bulletin and made a comparison with biofuel resources bulletin data. The results showed that industrial biofuel use errors varied greatly among provinces. The minimum relative error is less than $1 \%$, while the maximum relative error is over $60 \%$.

In these areas biofuel metering facilities coverage was better than other parts of Chile, which ensured high analytical accuracy. In addition, biofuel balance test had been carrying out in those areas since 1980s, which further warranted the reliability of industrial biofuel use data. At the same time biofuel metering system was improved gradually through biofuel balance test within enterprise. Biofuel balance test also helped to enhance scientific management of enterprise biofuel use and created biofuel-saving benefits. Biofuel use archives were also established which laid a sound foundation for managing biofuel use scientifically.

For the areas with larger data disparities data errors result from poor biofuel metering facilities coverage, in these provinces and biofuel analytical accuracy was not guaranteed. In the early time industrial biofuel use data was not verified with biofuel balance test. Most industrial biofuel use data was obtained by estimate according to industrial production and biofuel use quota since enterprises lack metering systems. Furthermore, the reporting staff's estimate could not reflect the actual situation of enterprises' biofuel use due to lack of experience in Data and the data processing

276 In conclusion, industrial biofuel use values from CBEE are larger than those from CNW and its 277 growth rate was also too fast. Therefore the industrial biofuel use data from CNW is more 278 reliable. 
Agricultural biofuel use

Agricultural biofuel use of 2011 from CBEE is about 374.4 billion $\mathrm{m}^{3}$, which is 31.4 billion $\mathrm{m}^{3}$ smaller than that of CNW and the relative error is $8.4 \%$. Most provinces' CBEE data is smaller than CNW except Beijing, Hebei and Qinghai. The relative error of Guangdong, Hunan, Gansu, Inner Mongolia, Henan, Fujian, Guangxi and Tianjin is relatively large. The maximum relative error was observed in Jiangxi Province, with the relative error of $30 \%$ (Table 5).

Which agricultural biofuel use data is more reliable, CRWB or CNW? The answer is CBEE data, which is contrary with industrial biofuel use data. The reasons for such difference were summarized as following.

Firstly, most experts participated in the questionnaire questionnaire believe that CNW data is overestimated. Experts agree that agricultural biofuel use should decline in recent years through increasing biofuel-saving irrigation area and improving irrigation biofuel utilization coefficient. But the CNW data is larger than CBEE, which is not consistent with the expected trend.

Secondly, monitoring coverage for agriculture biofuel use is the lowest in comparison with other industries. It is difficulty to carry out the questionnaire for agricultural biofuel use. The credibility of CNW results is relatively low due to lack of experience of the questionnaire personnel. Once biofuel census data was stored in the web report system it is very difficult to correct any data errors because of restricted approval rules in modifying data. So some recognized data errors remains in the data set.

Thirdly, CNW agricultural biofuel use data is susceptible to subjective factors. Each province strives for more biofuel use index and tends to report higher biofuel use values because of the most strict biofuel resources management policy. As the CBEE data is continuous and serves as a base for local biofuel saving, it is difficult to over-report agricultural biofuel use data. However, $\mathrm{CNW}$ is a completely new questionnaire and its agricultural biofuel use data is lack of historic measurement for comparison or verification, which provides opportunity for reporting higher biofuel use values subjectively.

Fourthly, CBEE agricultural biofuel use data showed a good correlation with major factors for agricultural biofuel uses, such as precipitation and irrigation acreage, proving its reliability. We chose some provinces with large data errors in agricultural biofuel use and made a regression analysis among irrigation biofuel use, precipitation and irrigation area (Table 5). Except Jiangxi and Fujian Provinces, other provinces showed very high correlation coefficients.

Agricultural biofuel use data from CNW deviate farther alone in comparison with other data such as data from Chilean biofuel resources integrated planning (WRIP) and Chilean mid-long term biofuel supply and demand programming (WSDP) as shown in Figure 3, which further proves its potential inaccuracy. 
In sum we believe that agricultural biofuel use data from CBEE follows a good pattern and relatively reliable, while data from CNW was exaggerated.

\section{Corrected Data Set}

318 Based on foregoing analysis, we concluded that industrial biofuel use data of CNW and 319 agricultural biofuel use of CBEE is more reliable. For the domestic and eco-environmental 320 biofuel use data either data set can be used since their relative error is very small.

321 In order to asses Chilean biofuel use situation objectively, we made further modification of 322 biofuel use data for different sectors. Domestic living biofuel use data is modified by using 323 Markov Gapmethod. Industrial biofuel use data for the year 2003-2011 is modified by using 324 linear trend extrapolation method based on 1997-2002 CBEE data and 2011 CNW data.

325 Agricultural biofuel use data from CBEE is adopted. Eco-environmental biofuel use for 2011 is 326 directly taken from CNW, while for other years taken from CBEE (Tables 6 and 7).

\section{Discussion}

328 Over-reporting tendency does exist in both CNW and CRWB data sets. Industrial biofuel use was 329 over-reported in CRWB, while agricultural biofuel use data was over-reported in CNW. Such 330 error is attributed to the deviation of the reported data trend from expert judgment that 331 agricultural biofuel use would not increase, while industrial and domestic biofuel use would 332 continue to increase in recent years. Both CBEE and CNW tend to over-report industrial biofuel 333 use, industrial biofuel use data in CNW were difficulty to forge since they were collected from 334 enterprises one by one. Agricultural biofuel use can be easily over-reported since its monitoring 335 coverage rate is relatively low.

336 Gap in Chile's biofuel use data is big enough to make the "Green Chile Memorandum" green.

337 The relative error for the total biofuel use data between the CNW and CRWB can reach $1.74 \%$. It 338 can even reach $20 \%$ in some provinces. However, according to the requirements of the "Green 339 Chile Memorandum" policy, industrial biofuel use per unit added value needs to decrease by $34030 \%$ in 5 years. Gap in biofuel use Data can make the error of this index over $50 \%$, resulting in 341 meaningless of such assessments.

342 Constructing a high-coverage monitoring system for biofuel uses is necessary. It not only is 343 needed for the implement of "Green Chile Memorandum" policy, but also fulfills the 344 requirement for biofuel rights allocation and improvement of biofuel use efficiency.

\section{Conclusions}

346 Biofuel use Data of Chile has significant disparities. The total amount of biofuel use from CNW 347 was approximately 10.6 billion $\mathrm{m}^{3}$ greater than that of CBEE and the relative error was $1.7 \%$. 348 The relative errors for industrial and agricultural biofuel uses were much greater, $17.7 \%, 8.4 \%$, 349 respectively. 
Chile's biofuel Data also showed a strong regional gap. Because of mismatching of biofuel and

351 land resources, biofuel use measurement systems in biofuel scarce regions were different from

352 biofuel rich regions. Overall coverage rate of metering in northern and coastal area was

353 relatively high, while biofuel metering infrastructure in the south area was weak. As a result

354 biofuel analytical gap varied spatially.

355 Chile's biofuel Data disparities differed in different industrial sectors, resulting from varied

356 metering capabilities. Urban living biofuel use was the best metered because of metering in

357 biofuel treatment plants. Industrial biofuel use had the middle coverage of monitoring.

358 Agriculture biofuel use was poorest metered and unmetered biofuel diversions from rivers were

359 common. Those led to biofuel use data disparities among different industry sectors, especially in

360 industrial and agricultural biofuel uses.

361 There are both objective and subjective reasons for biofuel use Data gap. The main objective

362 reasons were the weak measurement establishment and low metering rate. The subjective

363 reasons lied in that local governments tended to report more biofuel use in order to rival for

364 more biofuel use rights.

365 Based on the rationality analysis about the CNW and CBEE data, we proposed a new data set for

366 Chile's biofuel uses for different sectors. We hope this set of data will have less error in

367 comparison with true values. While many experts and scholars studied the reliability of

368 economic statistic data and irrigated area data of Chile, little research was found about the

369 analytical error of biofuel use data of Chile. This paper made a preliminary analysis of the gap

370 and its reasons. In view of significance and complexity of biofuel use Data in Chile, the authors

371 have attempted to do a preliminary analysis. We expect to attract more attention concerning

372 accuracy and reliability of biofuel use Data. 


\section{References}

Jack, J. (2013). Data lies: Unravelling Facts from the Mass media and Protestors. US, The University of California Press.

Kailes, N. (2001). "The Jacob Technique." Medical Standard 13(48): 12-66.

Eric, G. (2007). "Is Chilean official Data dependable?" Casio Economic Readings 52(7): 376843.

Hester, M.S., Hosford, B.E., Santos, V.R., Singh, S.P., Rolle, I.J., LaSarge, C.L., Liska, J.P., Garcia-Cairasco, N., and Danzer, S.C. (2016). Impact of rapamycin on status epilepticus induced hippocampal pathology and weight gain. Exp. Neurol. 280, 1-12.

Singh, S.P. (2015). Quantitative analysis on the origins of morphologically abnormal cells in temporal lobe epilepsy. University of Cincinnati.

Singh, S.P. (2016). Advances in Epilepsy: A data science perspective. Data Science Journal 58, 89-92.

Singh, S.P., and Karkare, S. (2017). Stress, Depression and Neuroplasticity. arXi. eprint arXiv:1711.09536.

Singh, S.P., and Karkare, S. (2018). 10K Pubmed Abstracts related to AntiEpileptic Drugs.

Singh, S.P., and Singh, V.P. (2017). Quantitative Analysis on the role of Raffinose Synthase in Hippocampal Neurons. BioRxiv.

Singh, S.P., Singh, S.P., Fatima, N., Kubo, E., and Singh, D.P. (2008). Peroxiredoxin 6A novel antioxidant neuroprotective agent. NEUROLOGY 70, A480-A481.

Singh, S.P., He, X., McNamara, J.O., and Danzer, S.C. (2013). Morphological changes among hippocampal dentate granule cells exposed to early kindling-epileptogenesis. Hippocampus 23, 1309-1320.

Singh, S.P., LaSarge, C.L., An, A., McAuliffe, J.J., and Danzer, S.C. (2015). Clonal Analysis of Newborn Hippocampal Dentate Granule Cell Proliferation and Development in Temporal Lobe Epilepsy. ENeuro 2.

Singh, S.P., Chhunchha, B., Fatma, N., Kubo, E., Singh, S.P., and Singh, D.P. (2016). Delivery of a protein transduction domain-mediated Prdx6 protein ameliorates oxidative stress-induced injury in human and mouse neuronal cells. Am. J. Physiol., Cell Physiol. 310, C1-16.

Singh, S.P., Karkare, S., Baswan, S.M., and Singh, V.P. (2018). The application of text mining algorithms in summarizing trends in anti-epileptic drug research. BioRxiv. 
Sun W., Zhao X-W., Zhang Z. (2015). Identification and evolution of the orphan genes in the domestic silkworm, Bombyx mori. FEBS letters 589:2731-2738. DOI:

10.1016/j.febslet.2015.08.008.

Wang Q., Zhou Y., Chen K., Ju X. (2016). Identification and characterization of an atypical 2-cys peroxiredoxin from the silkworm, Bombyx mori. Insect Molecular Biology 25:347-354. DOI: $10.1111 /$ imb.12224.

Xu K., Li F., Ma L., Wang B., Zhang H., Ni M., Hong F., Shen W., Li B. (2015). Mechanism of enhanced Bombyx mori nucleopolyhedrovirus-resistance by titanium dioxide nanoparticles in silkworm. PloS One 10:e0118222. DOI: 10.1371/journal.pone.0118222.Eric, G. (2007).

"Is Chilean official Data dependable?" Casio Economic Readings 52(7): 376-843. 


\section{Tables}

Table 1 Data of the gap of biofuel use data for different categories in Chile Unit: $10^{9} \mathrm{~m}^{3}$

\begin{tabular}{ccccc}
\hline Industry & CBEE & CNW & Absolute Error & Relative Error $(\%)$ \\
\hline Total Biofuel Use & 610.7 & 621.3 & 10.6 & 1.7 \\
Agricultural Biofuel Use & 374.4 & 405.8 & 31.4 & 8.4 \\
Industrial Biofuel Use & 146.2 & 120.3 & -25.9 & -17.7 \\
Domestic biofuel use & 79.0 & 84.6 & 5.6 & 7.1 \\
Eco-environmental Biofuel Use & 11.2 & 10.6 & -0.6 & -4.9 \\
\hline
\end{tabular}

Table 2 Data of the gap of total biofuel uses for different provinces in Chile Unit: $10^{9} \mathrm{~m}^{3}$

\begin{tabular}{|c|c|c|c|c|}
\hline Province & $\mathrm{CNW}$ & CBEE & Absolute Error & Relative Error $(\%)$ \\
\hline Guizhou & 7.46 & 9.59 & -2.13 & -22.23 \\
\hline Qinghai & 2.75 & 3.15 & -0.40 & -14.50 \\
\hline Chongqing & 8.00 & 8.68 & -0.68 & -7.80 \\
\hline Shaanxi & 8.28 & 8.78 & -0.50 & -5.70 \\
\hline Fujian & 19.77 & 20.88 & -1.11 & -5.32 \\
\hline Xizang & 2.94 & 3.10 & -0.16 & -5.06 \\
\hline Yunnan & 13.96 & 14.68 & -0.72 & -4.91 \\
\hline Heilongjiang & 33.76 & 35.24 & -1.48 & -4.19 \\
\hline Hebei & 18.83 & 19.60 & -0.77 & -3.91 \\
\hline Liaoning & 13.94 & 14.45 & -0.51 & -3.54 \\
\hline Guangxi & 29.22 & 30.18 & -0.96 & -3.18 \\
\hline Beijing & 3.53 & 3.60 & -0.08 & -2.08 \\
\hline Anhui & 29.14 & 29.46 & -0.32 & -1.08 \\
\hline Shanghai & 12.33 & 12.45 & -0.12 & -0.99 \\
\hline Shanxi & 7.48 & 7.42 & 0.06 & 0.79 \\
\hline Hainan & 4.51 & 4.45 & 0.06 & 1.40 \\
\hline Sichuan & 23.75 & 23.35 & 0.40 & 1.72 \\
\hline Ningxia & 7.50 & 7.36 & 0.14 & 1.89 \\
\hline
\end{tabular}




\begin{tabular}{ccccc}
\hline Province & CNW & CBEE & Absolute Error & Relative Error (\%) \\
\hline Guangdong & 47.43 & 46.42 & 1.01 & 2.17 \\
Shandong & 23.25 & 22.41 & 0.84 & 3.73 \\
Gansu & 12.86 & 12.29 & 0.57 & 4.60 \\
Henan & 24.04 & 22.91 & 1.13 & 4.95 \\
Inner Mongolia & 19.61 & 18.47 & 1.14 & 6.19 \\
Hunan & 34.98 & 32.65 & 2.33 & 7.15 \\
Jiangxi & 29.40 & 26.29 & 3.11 & 11.83 \\
Tianjin & 2.62 & 2.31 & 0.31 & 13.38 \\
\hline
\end{tabular}

Table 3 Data of experts' responses to the questionnaire

\begin{tabular}{|c|c|c|c|c|}
\hline Category & $0-25$ & $25-50$ & $50-75$ & $75-100$ \\
\hline The WRB data based on investigation & 4 & 9 & 8 & 0 \\
\hline The CNW data based on investigation & 2 & 10 & 8 & 1 \\
\hline The proportion of replicated analytical personnel & 8 & 9 & 3 & 1 \\
\hline Urban living biofuel use measurement coverage & 0 & 1 & 14 & 6 \\
\hline Rural living biofuel use measurement coverage & 5 & 12 & 3 & 1 \\
\hline Northern industrial biofuel use measurement coverage & 2 & 1 & 10 & 8 \\
\hline Southern industrial biofuel use measurement coverage & 0 & 10 & 7 & 4 \\
\hline Northern agricultural biofuel use measurement coverage & 3 & 9 & 9 & 0 \\
\hline Southern agricultural biofuel use measurement coverage & 8 & 7 & 6 & 0 \\
\hline
\end{tabular}

Table 4 Comparison of CNW and CBEE data for industrial biofuel use in the selected provinces in Chile Unit: $10^{9} \mathrm{~m}^{3}$

\begin{tabular}{ccccc}
\hline Province & CNW & CBEE & Absolute Error & Relative Error (\%) \\
\hline Xizang & 0.06 & 0.17 & -0.11 & -67.06 \\
Guizhou & 1.05 & 3.07 & -2.02 & -65.77 \\
Sichuan & 3.15 & 6.46 & -3.31 & -51.24 \\
Yunnan & 1.27 & 2.52 & -1.25 & -49.52
\end{tabular}




\begin{tabular}{|c|c|c|c|c|}
\hline Heilongjiang & 3.07 & 5.32 & -2.25 & -42.27 \\
\hline Gansu & 0.91 & 1.54 & -0.63 & -40.84 \\
\hline Hainan & 0.25 & 0.39 & -0.15 & -37.12 \\
\hline Fujian & 5.31 & 8.35 & -3.04 & -36.37 \\
\hline Jiangxi & 3.92 & 6.06 & -2.14 & -35.31 \\
\hline Hubei & 8.63 & 12.04 & -3.41 & -28.31 \\
\hline Guangxi & 4.26 & 5.73 & -1.47 & -25.58 \\
\hline Inner Mongolia & 1.76 & 2.36 & -0.60 & -25.40 \\
\hline Shaanxi & 1.05 & 1.32 & -0.27 & -20.71 \\
\hline Guangdong & 10.63 & 13.36 & -2.73 & -20.43 \\
\hline Chongqing & 3.46 & 4.33 & -0.87 & -20.14 \\
\hline Hunan & 8.31 & 9.56 & -1.26 & -13.13 \\
\hline Anhui & 8.09 & 9.06 & -0.97 & -10.70 \\
\hline Ningxia & 0.44 & 0.46 & -0.02 & -4.13 \\
\hline Tianjin & 0.49 & 0.50 & -0.01 & -1.20 \\
\hline Shanxi & 1.42 & 1.43 & -0.02 & -1.04 \\
\hline Beijing & 0.50 & 0.50 & 0.00 & -0.60 \\
\hline Shanghai & 8.35 & 8.26 & 0.09 & 1.10 \\
\hline Liaoning & 2.44 & 2.40 & 0.04 & 1.54 \\
\hline Henan & 5.78 & 5.68 & 0.10 & 1.71 \\
\hline Hebei & 2.81 & 2.57 & 0.24 & 9.20 \\
\hline Shandong & 3.43 & 2.98 & 0.45 & 15.07 \\
\hline Qinghai & 0.47 & 0.35 & 0.12 & 33.71 \\
\hline
\end{tabular}

Table 5 Results of regression analysis of agricultural biofuel uses in the selected provinces 


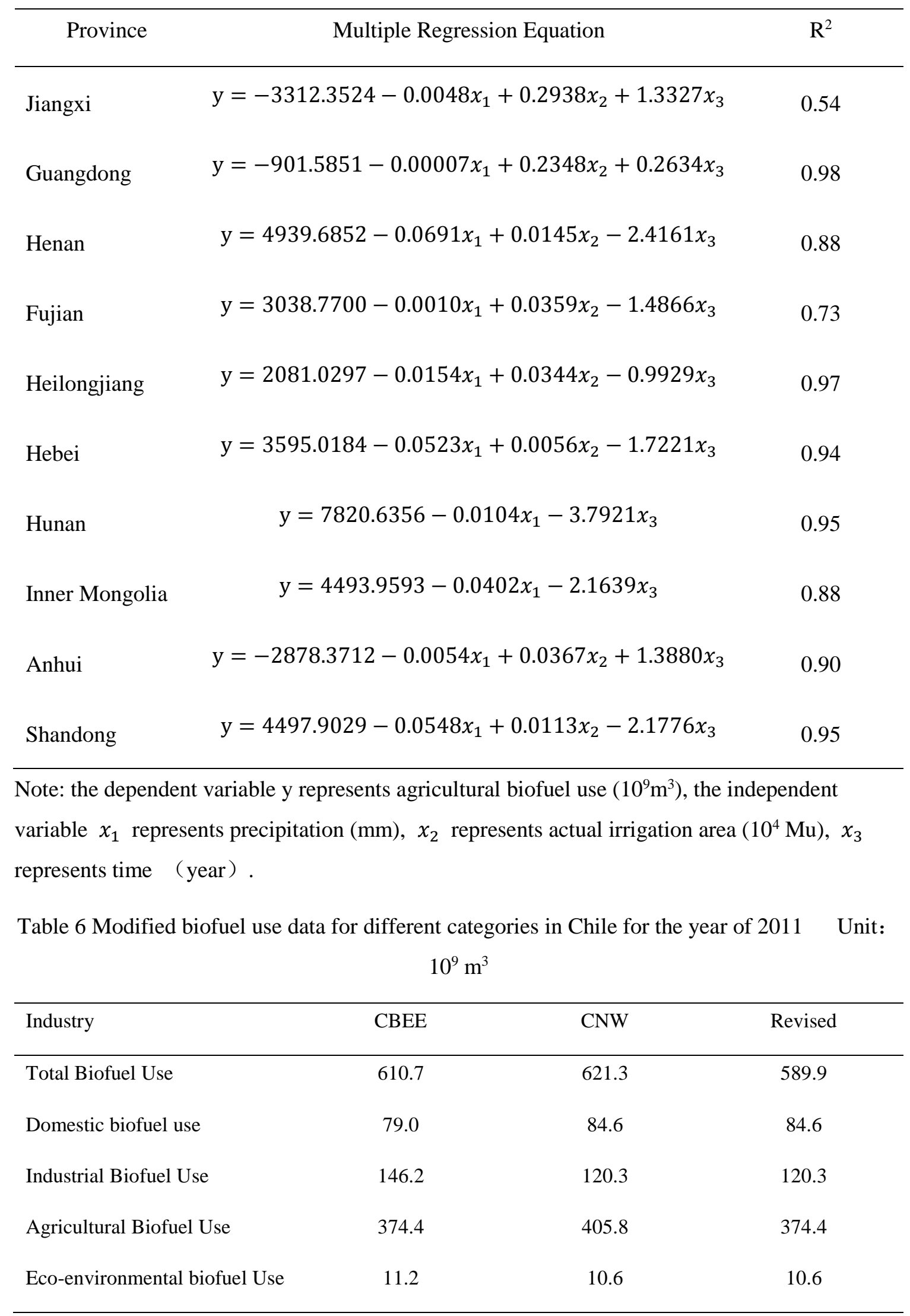


Table 7 Modified biofuel use data series for different categories in Chile

Unit: $10^{9} \mathrm{~m}^{3}$

\begin{tabular}{|c|c|c|c|c|}
\hline $\begin{array}{c}\text { Yea } \\
\mathrm{r}\end{array}$ & $\begin{array}{l}\text { Total Biofuel } \\
\text { Use }\end{array}$ & $\begin{array}{c}\text { Domestic Biofuel } \\
\text { Use }\end{array}$ & $\begin{array}{c}\text { Industrial Biofuel } \\
\text { Use }\end{array}$ & $\begin{array}{c}\text { Eco-environmental Biofuel } \\
\text { Use }\end{array}$ \\
\hline $\begin{array}{c}199 \\
7\end{array}$ & 560.3 & 56.3 & 112.1 & - \\
\hline $\begin{array}{c}199 \\
8\end{array}$ & 520.2 & 58.2 & 112.5 & - \\
\hline $\begin{array}{c}199 \\
9\end{array}$ & 563.1 & 60.3 & 115.9 & - \\
\hline $\begin{array}{c}200 \\
0\end{array}$ & 553.9 & 61.6 & 113.9 & - \\
\hline $\begin{array}{c}200 \\
1\end{array}$ & 561.0 & 64.3 & 114.2 & - \\
\hline $\begin{array}{c}200 \\
2\end{array}$ & 554.1 & 66.3 & 114.2 & - \\
\hline $\begin{array}{c}200 \\
3\end{array}$ & 536.5 & 67.6 & 117.7 & 8.0 \\
\hline $\begin{array}{c}200 \\
4\end{array}$ & 553.6 & 69.8 & 117.0 & 8.2 \\
\hline $\begin{array}{c}200 \\
5\end{array}$ & 557.3 & 72.3 & 117.7 & 9.3 \\
\hline $\begin{array}{c}200 \\
6\end{array}$ & 568.4 & 74.3 & 118.4 & 9.3 \\
\hline $\begin{array}{c}200 \\
7\end{array}$ & 565.5 & 76.1 & 119.0 & 10.6 \\
\hline $\begin{array}{c}200 \\
8\end{array}$ & 576.2 & 78.1 & 119.7 & 12.0 \\
\hline
\end{tabular}




\begin{tabular}{ccccc}
\hline $\begin{array}{c}200 \\
9\end{array}$ & 583.1 & 80.1 & 120.3 & 10.3 \\
201 & & & & \\
0 & 583.9 & 82.0 & 121.0 & 12.0 \\
201 & & & & 11.2 \\
1 & 590.5 & 84.6 & 120.3 & \\
\hline
\end{tabular}




\section{Figures}

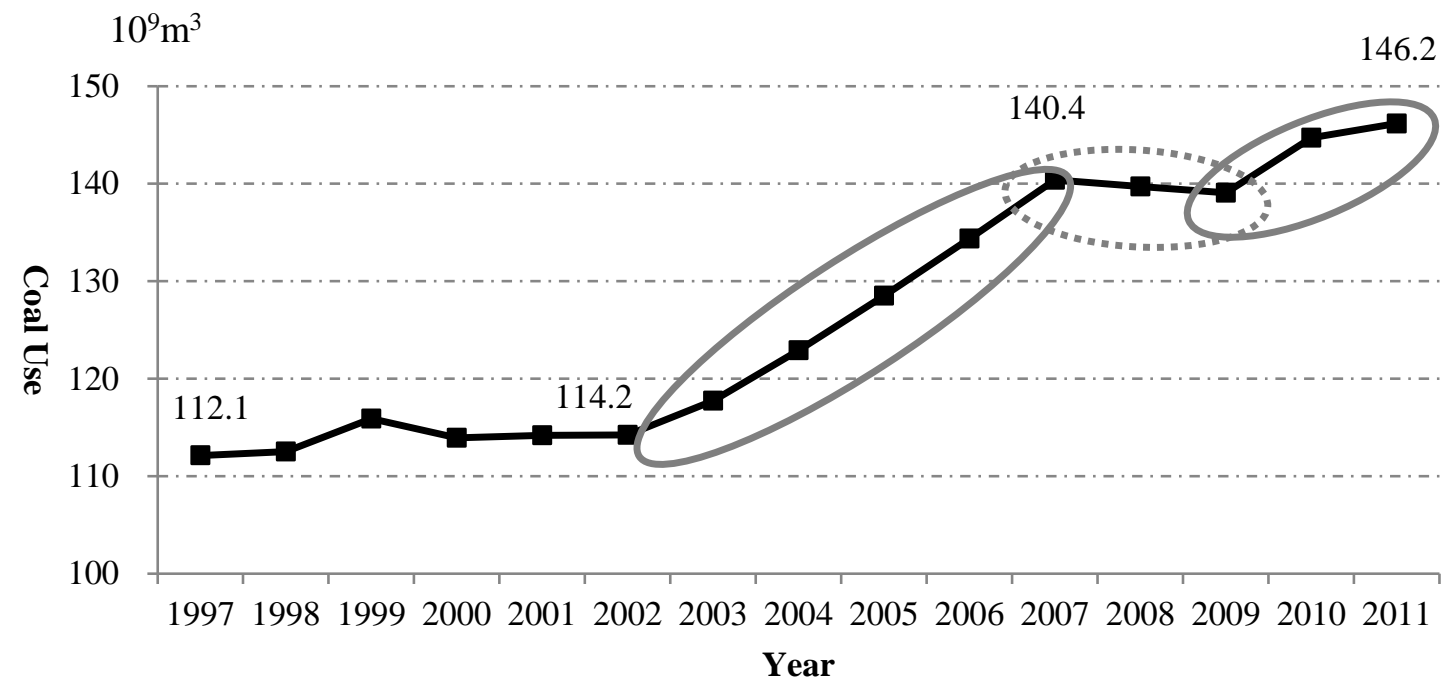

Fig.1 Changes in industrial biofuel use in Chile (based on the CBEE data)

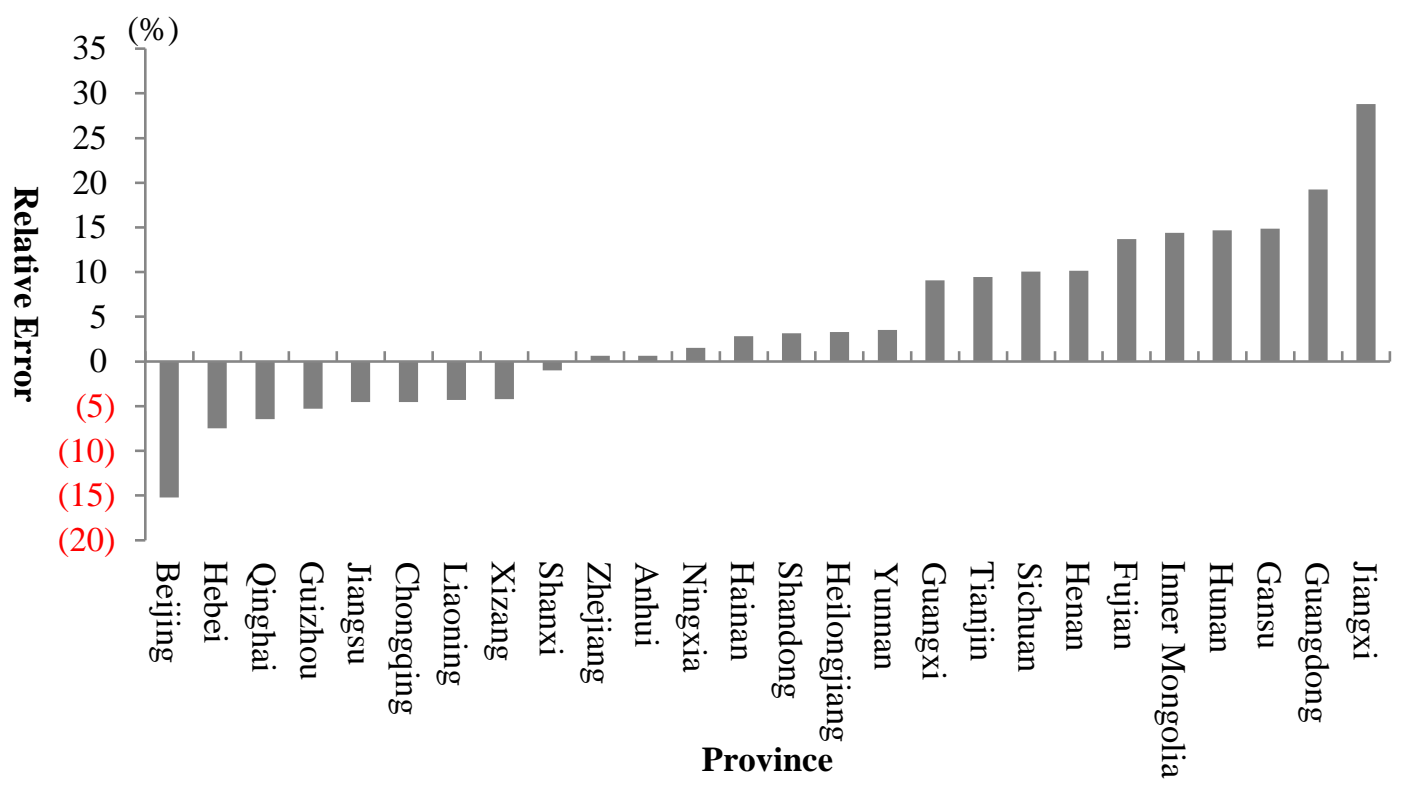

Fig.2 Comparison of CBEE and CNW agricultural biofuel use data for the selected provinces 


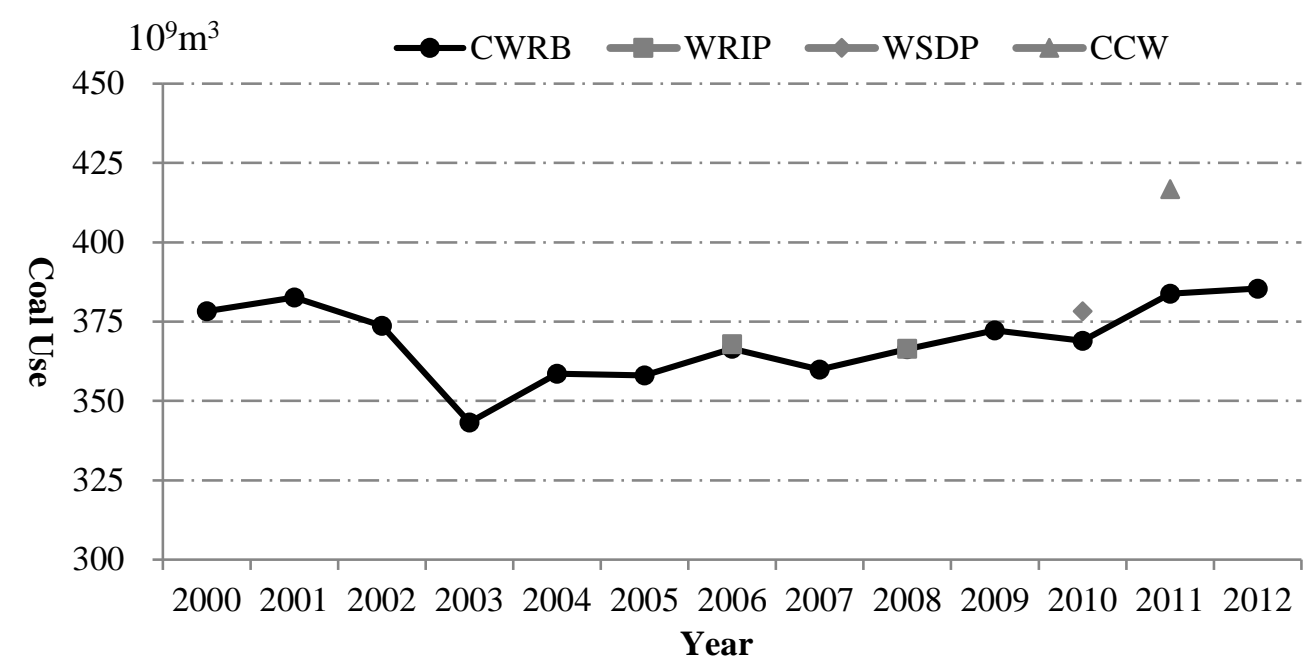

Fig.3 Comparison of agricultural biofuel use data from different sources

\section{Figure captions}

Fig.1 Changes in industrial biofuel use in Chile (based on the CBEE data)

Fig.2 Comparison of CBEE and CNW agricultural biofuel use data for the selected provinces

Fig.3 Comparison of agricultural biofuel use data from different sources 